\title{
Effects of BAK-free travoprost treatment for 3 years in patients with normal tension glaucoma
}

This article was published in the following Dove Press journal:

Clinical Ophthalmology

14 August 2012

Number of times this article has been viewed

\section{Kenji Inoue \\ Mayumi Iwasa' \\ Masato Wakakura' \\ Goji Tomita ${ }^{2}$ \\ 'Inouye Eye Hospital, ${ }^{2}$ Toho University Ohashi Medical Center, Tokyo, Japan}

Background: The purpose of this study was to evaluate the effects of benzalkonium (BAK)-free travoprost monotherapy administered for 3 years on intraocular pressure and visual field performance.

Methods: The intraocular pressure of 76 patients with normal tension glaucoma was monitored every 1-3 months. A Humphrey visual field test was performed every 6 months after treatment and compared with the results before treatment. Visual field performance was also evaluated by trend and event analysis.

Results: Thirty cases discontinued within 3 years. Mean intraocular pressure after 3 years of travoprost treatment $(14.1 \pm 2.4 \mathrm{mmHg})$ was significantly lower than that before treatment $(16.8 \pm 2.6 \mathrm{mmHg}, P<0.0001)$. There was no change in the mean deviation and pattern standard deviation as measured by Humphrey visual field test after 3 years of treatment compared with before treatment. Visual field performance was worse in one patient $(2.8 \%)$ by trend analysis and five patients $(13.9 \%)$ by event analysis. Treatment was discontinued in six cases $(7.9 \%)$ due to the appearance of adverse reactions.

Conclusion: BAK-free travoprost monotherapy was effective in reducing intraocular pressure for at least 3 years; however, visual field performance worsened in $2.8 \%-13.9 \%$ of patients with normal tension glaucoma.

Keywords: BAK-free travoprost, intraocular pressure, visual field, trend analysis, event analysis

\section{Introduction}

There is good evidence for the efficacy of ocular pressure-lowering therapy for visual field preservation in patients with normal tension glaucoma. ${ }^{1,2}$ Typically, treatment with eye drops is the first choice for reducing intraocular pressure (IOP). Because of their powerful IOP-lowering efficacy, very few adverse reactions in the body, and convenience of once-daily administration, prostaglandin analogs are the drugs of first choice. However, there are adverse reactions to the eye drops, and in particular, injury to the surface of the eye due to benzalkonium (BAK) is a common problem. ${ }^{3}$ Travoprost was one of the first BAK-containing prostaglandin analogs to be released. Subsequently, a BAK-free version of the drug was developed. Some studies have reported no significant difference in the IOP-lowering effect between BAK-containing and BAK-free eye drops., ${ }^{4,5}$

During follow-up, IOP in patients with glaucoma is examined to confirm the IOPlowering efficacy of eye drops, and the visual field is examined to confirm the existence or nonexistence of visual field defect progression. Normal tension glaucoma is a chronic
Correspondence: Kenji Inoue Inouye Eye Hospital, 4-3 KandaSurugadai, Chiyoda-ku,

Tokyo I0I-0062, Japan

Tel +8I 332950911

Fax +8I 332950917

Email inoue-k@inouye-eye.or.jp 
progressive disease; however, visual field defect progression is usually slow. Therefore, evaluation is not easy, and longterm follow-up is required. There are many methods used to evaluate the progression of visual field defects, including clinical judgment, the criterion method, the staging method, linear regression analysis (trend analysis), and event analysis. Because the evaluation methods for visual field defect progression differ, progression is extremely difficult to assess.

In the present study, we prospectively evaluated the changes in IOP and progression of visual field defects over a 3-year period while administering BAK-free travoprost eye drop monotherapy in patients with normal tension glaucoma.

\section{Materials and methods}

We studied 76 eyes from 76 patients (33 men and 43 women) diagnosed with normal tension glaucoma and prescribed BAK-free travoprost eye drop monotherapy from March 2008 through April 2009. There were no cases where other medications were used before administration of BAK-free travoprost. Subjects who fulfilled the diagnostic criteria and did not meet the exclusion criteria were followed-up for 3 years. Their mean age was $54.8 \pm 13.9$ (range 26-83) years. The diagnostic criteria for normal tension glaucoma were IOP under $21 \mathrm{mmHg}$ measured several times (including during diurnal variation), glaucomatous optic disc (diffuse or focal thinning of the neuroretinal rim), and highly reliable and repeatable detection of an abnormal glaucomatous visual field. Exclusion criteria were as follows: corrected visual acuity of less than 10/20, a history of intraocular surgery, laser surgery, steroid therapy (local or whole body), or a disorder recognized by otorhinology or neurosurgery examination. In this study, one eye was considered one case; if both eyes of a patient fulfilled the diagnostic criteria and did not meet the exclusion criteria, the right eye was used.

BAK-free travoprost eye drops were administered once a day at night. Every 1-3 months, IOP was measured using the Goldmann applanation tonometer at almost the same time. Every 6 months, the visual field was tested using a Humphrey visual field 30-2 Sita-Standard test. Cases were excluded from the analysis if they were false-positive or false-negative, or poor fixation was over $20 \%$. Adverse reactions were examined at every follow-up visit. The definition for discontinuation was the point where follow-up was not possible or where there were changes in eye drops because of appearance of adverse reactions or IOP-decreasing efficacy was inadequate. Furthermore, persistence with BAK-free travoprost eye drops was analyzed using the Kaplan-Meier method. The study aims and content were adequately explained to all patients, and consent was obtained before each examination was performed.

One-way repeated-measures analysis of variance and multiple comparisons (Bonferroni and Dunnett's test) were used to compare values at baseline and 6, 12, 18, 24, 30, and 36 months after treatment with BAK-free travoprost, as well as the mean deviation value and pattern standard deviation value for visual field testing (at baseline and at years 1, 2, and 3 thereafter). The significance level was set at $P<0.05$. Trend analysis $^{6}$ and event analysis ${ }^{7}$ were also used to evaluate visual field defect progression. For trend analysis, the index was expressed as the chronological change in mean deviation, which was analyzed by linear regression and was calculated on an annual basis. ${ }^{6}$ Variation in mean deviation value $(\mathrm{dB} /$ year) was calculated on an annual basis, and expressed according to its statistical significance. In the event analysis, the first two follow-up examinations were considered to be the baseline. ${ }^{7}$ Baseline and subsequent examinations were subsequently compared. If deterioration beyond a certain level $(P<0.05)$ was recognized, the index was used to judge progression. Glaucoma progression analysis was used. If a significant decrease was documented at three or more adjacent measurement points and two times in succession, then the "possibility of progression" was confirmed. If a significant decrease was documented in three or more adjacent measurement points and three times successively, then "tendency to progression" was confirmed. In the present study, when a tendency to progression was confirmed, visual field defect progression was also confirmed.

\section{Results}

The background of the patients is shown in Table 1. Evaluation of IOP was done for 46 cases and visual field evaluation was done for 37 cases. The mean IOP at each time point decreased significantly compared with baseline $(P<0.0001$, Table 2$)$. The mean deviation value for the

Table I Background of patients

\begin{tabular}{lll}
\hline Type of glaucoma & $\begin{array}{l}\text { Normal tension } \\
\text { glaucoma }\end{array}$ & Range \\
\hline Gender & $\begin{array}{l}\text { Men 33, women } 43 \\
\text { Age }\end{array}$ & $54.8 \pm 13.9$ years \\
IOP before administration & $16.8 \pm 2.6 \mathrm{mmHg}$ & $(26-83$ years $)$ \\
MD before administration & $-5.4 \pm 4.7 \mathrm{~dB}$ & $(-26.3-1.4 \mathrm{mmH})$ \\
PSD before administration & $7.4 \pm 4.2 \mathrm{~dB}$ & $(2.1-17.0 \mathrm{~dB})$ \\
Refraction value & $-3.9 \pm 3.9 \mathrm{D}$ & $(-16.0-+3.5 \mathrm{D})$ \\
\hline
\end{tabular}

Abbreviations: IOP, intraocular pressure; MD, mean deviation; PSD, pattern standard deviation. 
Table 2 The mean IOP before and after administration

\begin{tabular}{lll}
\hline Period of time & $\begin{array}{l}\text { Intraocular pressure } \\
(\mathbf{m m H g})\end{array}$ & $\boldsymbol{P}$ value \\
\hline Baseline & $16.8 \pm 2.6$ & \\
6 months & $13.6 \pm 2.5$ & $<0.000 \mathrm{I}$ \\
I year & $13.5 \pm 2.1$ & $<0.000 \mathrm{I}$ \\
I year 6 months & $13.5 \pm 2.0$ & $<0.000 \mathrm{I}$ \\
2 years & $13.6 \pm 2.7$ & $<0.000 \mathrm{I}$ \\
2 years 6 months & $13.7 \pm 2.6$ & $<0.000 \mathrm{I}$ \\
3 years & $14.0 \pm 2.4$ & $<0.000 \mathrm{I}$ \\
\hline
\end{tabular}

Abbreviation: IOP, intraocular pressure.

visual field was similar between baseline and after treatment at each time point $(P=0.107$, Table 3$)$. The mean pattern standard deviation value for the visual field was similar between baseline and after treatment at each time point $(P=0.057$, Table 3$)$.

Thirty of the original 76 patients dropped out of the study, and three cases in which Goldmann visual field perimetry was used and six cases for which reliable test results were not obtained more than 5 times were omitted from the study. Trend analysis and event analysis were performed in the remaining 37 cases. One case $(2.8 \%)$ was judged to have a progression tendency in the trend analysis, and five cases $(13.9 \%)$ were judged to have a progression tendency in the event analysis (Figure 1). One case had visual field defect progression on both trend analysis and event analysis.

Thirty patients (39.5\%) discontinued the eye drops during the 3-year follow-up period. The reasons for discontinuation were as follows: 16 patients stopped coming to the hospital, two had to change hospitals because of relocation, one discontinued the eye drops due to cataract surgery, one became pregnant, four added other eye drops because of inadequate IOP reduction, and six discontinued due to adverse reactions (three cases of eyelid pigmentation, one of hyperemia, one of eye discharge, and one of uveitis). No patient reported the appearance of deepening of the upper eyelid sulcus. The persistence rate with BAK-free travoprost is shown on Figure 2, and was $77.6 \%$ after one year, $65.8 \%$ after 2 years, and $60.5 \%$ after 3 years.

\section{Discussion}

The IOP decrease and IOP decrease rate when BAK-containing travoprost eye drop monotherapy was administered long term (for more than 6 months) have been reported to be 2.5-9.3 mmHg and $16.1 \%-36.6 \%$, respectively. ${ }^{8-15}$ However, the studies reported have included many cases of ocular hypertension, open-angle glaucoma, pigmentary glaucoma, and pseudoexfoliation glaucoma, ${ }^{8-13}$ with few cases of normal tension glaucoma ${ }^{14,15}$ as in the present study. For studies in which subjects had ocular hypertension, open-angle glaucoma, pigmentary glaucoma, or pseudoexfoliation glaucoma, the IOP decrease was $6.3-9.3 \mathrm{mmHg}$, the IOP decrease rate was $25.2 \%-36.6 \%$, and IOP before treatment was 24.3-27.4 mmHg, which is a high value. ${ }^{8-13}$ In contrast, for two studies in which subjects had normal tension glaucoma, the IOP decrease was $2.5 \mathrm{mmHg}^{14}$ and $2.71 \mathrm{mmHg}^{15}$ and the IOP decrease rate was $16.1 \%{ }^{14}$ and $18.3 \%{ }^{15}$ However, there are no previous reports on the efficacy of long-term BAKfree travoprost eye drop monotherapy for lowering IOP. In the present study, IOP decreased by $2.9 \pm 2.0 \mathrm{mmHg}$ and the IOP decrease rate was $19.8 \% \pm 17.8 \%$ after 3 years of treatment with BAK-free travoprost eye drops in patients with normal tension glaucoma. The results may be lower in studies that included subjects with ocular hypertension, open-angle glaucoma, pigmentary glaucoma, and pseudoexfoliation glaucoma; ${ }^{8-13}$ however, there may be no significant difference when the subjects have normal tension glaucoma. ${ }^{14,15}$ The reason for this is that, in the present study, IOP was lower before treatment $(16.8 \pm 2.6 \mathrm{mmHg})$ than in patients with ocular hypertension, open-angle glaucoma, pigmentary glaucoma, or pseudoexfoliation glaucoma $(24.3-27.4 \mathrm{mmHg}) \cdot{ }^{8-13}$ There was no significant difference when compared with patients who had normal tension glaucoma (14.79-15.0 mmHg). ${ }^{14,15}$ Because there is a difference in subjects, treatment duration, and pretreatment IOP, we are not able to compare past reports of efficacy accurately. However, the results of the present study indicate that there is no significant difference in IOPlowering effect over a long period between BAK-free travoprost eye drops and BAK-containing travoprost eye drops.

There are reports of short-term administration of BAKfree travoprost for normal-tension glaucoma. ${ }^{16}$ Nomura et al administered BAK-free travoprost for 1-2 months and IOP was measured 24 hours before and after treatment. ${ }^{16}$ Mean IOP was $12.9 \pm 2.2 \mathrm{mmHg}$ at 24 hours before administration. IOP after administration $(10.3 \pm 2.0 \mathrm{mmHg})$ was significantly

Table 3 Mean deviation (MD) and pattern standard deviation (PSD)

\begin{tabular}{lllccc}
\hline & Baseline & I year & 2 years & 3 years & P value \\
\hline MD value & $-5.4 \pm 4.7 \mathrm{~dB}$ & $-4.4 \pm 4.4 \mathrm{~dB}$ & $-4.7 \pm 4.7 \mathrm{~dB}$ & $-4.5 \pm 4.4 \mathrm{~dB}$ & 0.107 \\
PSD value & $7.4 \pm 4.2 \mathrm{~dB}$ & $6.9 \pm 4.3 \mathrm{~dB}$ & $7.2 \pm 4.7 \mathrm{~dB}$ & $7.9 \pm 4.8 \mathrm{~dB}$ & 0.057 \\
\hline
\end{tabular}




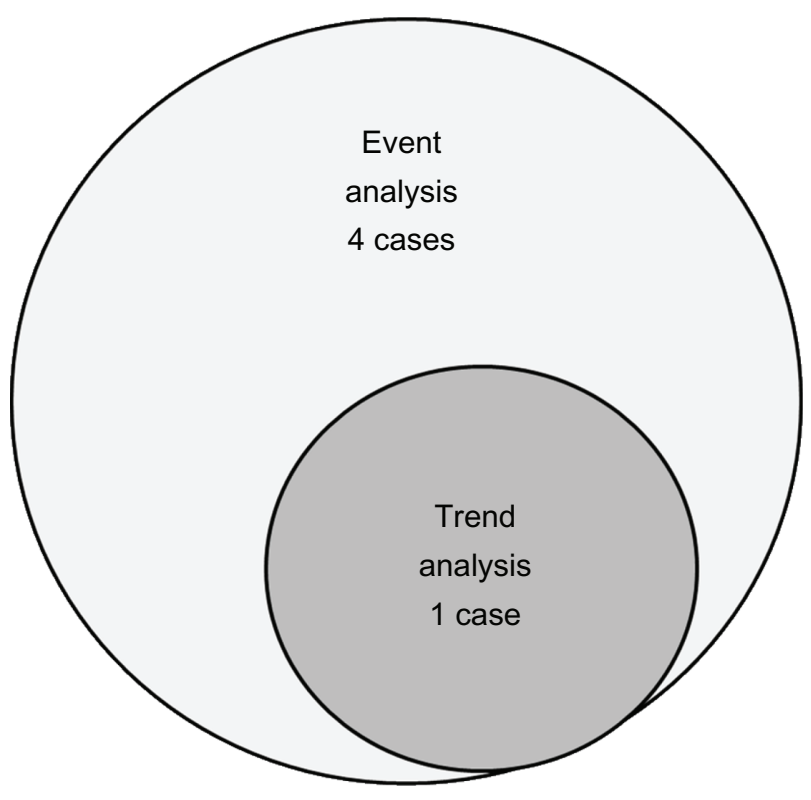

Figure I Trend and event analysis of advanced visual field defects.

decreased when compared with pretreatment levels. The mean IOP decrease rate was $20.2 \%$. There are reports of comparison of patients with open-angle glaucoma administered BAKfree travoprost or latanoprost. ${ }^{17,18}$ Sawada et al administered BAK-free travoprost and latanoprost in a crossover manner for 12 weeks each, and there was no significant difference in IOP-decreasing efficacy. ${ }^{17}$ Aihara et al switched patients from latanoprost to BAK-free travoprost and observed their IOP for 12 months. ${ }^{18}$ IOP significantly decreased after treatment for one, 3 , and 12 months compared with pretreatment levels. There have been reports of short-term administration in normal-tension glaucoma patients ${ }^{16}$ and long-term reports of change on latanoprost ${ }^{17,18}$ but there have been no reports of long-term administration of BAK-free travoprost in patients with normal-tension glaucoma.

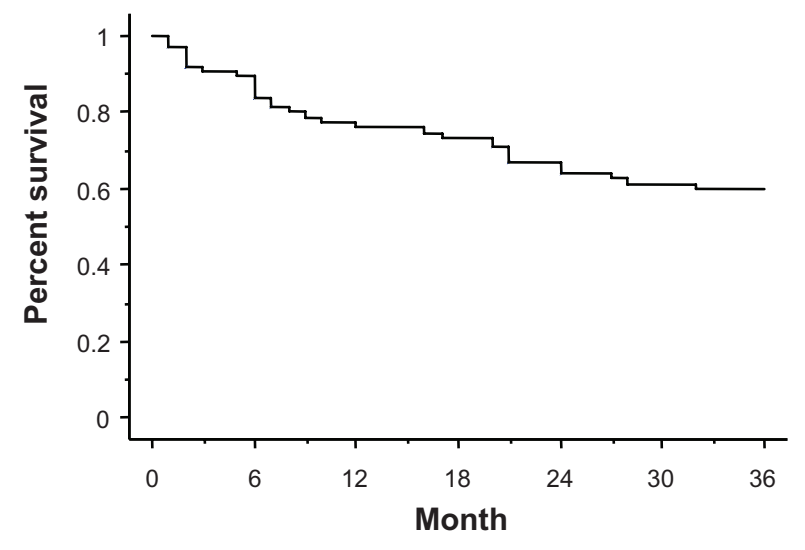

Figure 2 Kaplan-Meier analysis.
The reported adverse reactions for BAK-containing eye drops were conjunctival hyperemia, pain, discomfort, pruritus, visual acuity decrease, stinging, foreign body sensation, uveitis, hypertrichosis, periocular hyperpigmentation, superior sulcus deepening, and iris pigmentation. ${ }^{8-15}$ Adverse reactions in the present study (eyelid pigmentation, hyperemia, eye discharge, and uveitis) were the same as those in previous studies. ${ }^{8-15}$ Discontinuation rates due to adverse reactions have been reported to be $0 \%,{ }^{8,9} 0.1 \%,{ }^{10} 4.5 \%{ }^{11}$, $4.6 \%,{ }^{12} 5.0 \%,{ }^{14} 11.1 \%,{ }^{15}$ and $16.7 \% .{ }^{13}$ Because the treatment periods are different we cannot compare them; however, in our study, $7.9 \%$ of patients discontinued treatment because of adverse reactions, which is almost the same as the percentages in previous studies. ${ }^{8-15}$ The results of the present study indicate that there was no significant difference in the safety of BAK-free and BAK-containing travoprost eye drops.

There are no reports of visual field defects during longterm administration of travoprost eye drops. We compared the mean deviation and pattern standard deviation values of treatment for 3 years, and there was no difference before and after treatment. However, event analysis and trend analysis of each case showed progression in $13.9 \%$ and $2.8 \%$ of patients, respectively. In previous studies, we investigated visual field defects in patients with normal tension glaucoma treated with $\beta$-blockers using event analysis and trend analysis. ${ }^{19,20}$ In a 5-year follow-up of levobunolol eye drop administration, visual field defect progression was seen in $30 \%$ and $15 \%$ of patients in event analysis and trend analysis, respectively. ${ }^{19}$ In a 5 -year follow-up of treatment with nipradilol eye drops, visual field defect progression was seen in $16 \%$ of patients in both event and trend analysis. ${ }^{20}$ The results of the event and trend analysis in the present study might be slightly better than previous ones. The reason for this is because the administration period was shorter in the present study (3 years) than in previous studies (5 years). ${ }^{19,20}$ Moreover, the IOP-lowering efficacy of treatment for 3 years in the present study $(19.8 \% \pm 17.8 \%)$ was slightly higher than that in previous studies $\left(18.2 \% \pm 12.8 \%{ }^{19}\right.$ and $17.2 \% \pm 10.3 \%{ }^{20}$ ).

In conclusion, when BAK-free travoprost eye drop monotherapy was administered to patients with normal tension glaucoma for 3 years, IOP decreased significantly. However, there was visual field defect progression in $2.8 \%-13.9 \%$ of cases. Adverse reactions appeared in $7.9 \%$ of cases, and the eye drops were discontinued.

\section{Disclosure}

The authors report no conflicts of interest in this work. 


\section{References}

1. Collaborative Normal-Tension Glaucoma Study Group. Comparison of glaucomatous progression between untreated patients with normaltension glaucoma and patients with therapeutically reduced intraocular pressure. Am J Ophthalmol. 1998;126(4):487-497.

2. Collaborative Normal-Tension Glaucoma Study-Group. The effectiveness of intraocular pressure reduction in the treatment of normal-tension glaucoma. Am J Ophthalmol. 1998;126(4):498-505.

3. Gusset AR. Benzalkonium chloride toxicity to the human cornea. Am J Ophthalmol. 1977;84(2):169-171.

4. Lewis RA, Katz GJ, Weiss MJ, et al. Travoprost $0.004 \%$ with and without benzalkonium chloride: a comparison of safety and efficacy. J Glaucoma. 2007;16(1):98-103.

5. Gross RL, Peace JH, Smith SE, et al. Duration of IOP reduction with travoprost BAK-free solution. J Glaucoma. 2008;17(3): 217-222.

6. McNaught AL, Crabb DP, Fitzke FW, Hitchings RA. Visual field progression: comparison of Humphrey Statpac 2 and pointwise linear regression analysis. Graefes Arch Clin Exp Ophthalmol. 1996;234(7):411-418.

7. Flammer J, Drance SM, Augustiny L, Funkhouser A. Quantification of glaucomatous visual field defects with automated perimetry. Invest Ophthalmol Vis Sci. 1985;26(2):176-181.

8. Macky TA. Bimatoprost versus travoprost in an Egyptian population: a hospital-based prospective, randomized study. J Ocul Pharmacol Ther. 2010;26(6):605-610.

9. Netland PA, Landry T, Sullivan EK, et al. Travoprost compared with latanoprost and timolol in patients with open-angle glaucoma or ocular hypertension. Am J Ophthalmol. 2001;132(4):472-484.

10. Netland PA, Robertson SM, Sullivan EK, et al. Response to travoprost in black and nonblack patients with open-angle glaucoma or ocular hypertension. Adv Ther. 2003;20(3):149-163.
11. Fellman RL, Sullivan EK, Ratliff M, et al. Comparison of travoprost $0.0015 \%$ and $0.004 \%$ with timolol $0.5 \%$ in patients with elevated intraocular pressure. Ophthalmology. 2002;109(5):998-1008.

12. Goldberg I, Cunha-Vaz J, Ratliff M, et al. Comparison of topical travoprost eye drops given once daily and timolol $0.5 \%$ given twice daily in patients with open- angle glaucoma or ocular hypertension. J Glaucoma. 2001;10(5):414-422.

13. Parmaksiz S, Yüsel N, Karabas VL, Özkan B, Dermirci G, Caglar Y. A comparison of travoprost, latanoprost, and the fixed combination of dorzolamide and timolol in patients with pseudoexfoliation glaucoma. Eur J Ophthalmol. 2006;16(1):73-80.

14. Ang GS, Kersey JP, Shepstone L, Broadway DC. The effect of travoprost on daytime intraocular pressure in normal tension glaucoma: a randomized controlled trial. Br J Ophthalmol. 2008;92(8):1129-1133.

15. Suh MH, Park KH, Kim DH. Effect of travoprost on intraocular pressure during 12 months of treatment for normal-tension glaucoma. Jpn J Ophthalmol. 2009;53(1):18-23.

16. Nomura Y, Nakakura S, Moriwaki M, Takahashi Y, Shiraki K. Effect of travoprost on 24-hour intraocular pressure in normal tension glaucoma. Clin Ophthalmol. 2010;4:643-647.

17. Sawada A, Yamamoto T, Takatsuka N. Randomized crossover study of latanoprost and travoprost in eyes with open-angle glaucoma. Graefes Arch Clin Exp Ophthalmol. 2012;250(1):123-129.

18. Aihara M, Otani S, Kozaki J, et al. Long-term effect of BAK-free travoprost on ocular surface and intraocular pressure in glaucoma patients after transition from latanoprost. J Glaucoma. 2012;21(1):60-64.

19. Inoue K, Wakakura M, Tomita G. Effects of levobunolol treatment in patients with normal-tension glaucoma for 5 years. Folia Japonica de Ophthalmologica Clinica. 2011;4(2):115-119.

20. Inoue K, Noguchi K, Wakakura M, Tomita G. Effect of five years of treatment with nipradilol eye drops in patients with normal tension glaucoma. Clin Ophthalmol. 2011;5:1211-1216.
Clinical Ophthalmology

\section{Publish your work in this journal}

Clinical Ophthalmology is an international, peer-reviewed journal covering all subspecialties within ophthalmology. Key topics include: Optometry; Visual science; Pharmacology and drug therapy in eye diseases; Basic Sciences; Primary and Secondary eye care; Patient Safety and Quality of Care Improvements. This journal is indexed on

Submit your manuscript here: http://www.dovepress.com/clinical-ophthalmology-journal

\section{Dovepress}

PubMed Central and CAS, and is the official journal of The Society of Clinical Ophthalmology (SCO). The manuscript management system is completely online and includes a very quick and fair peer-review system, which is all easy to use. Visit http://www.dovepress.com/ testimonials.php to read real quotes from published authors. 